\title{
Exogenous SPARC Suppresses Proliferation and Migration of Prostate Cancer by Interacting With Integrin $\beta$ I
}

\author{
Minkyoung Shin, ${ }^{1}$ Atsushi Mizokami, ${ }^{1 *}$ Jungim Kim, ${ }^{1}$ Mitsuo Ofude, ${ }^{1}$ Hiroyuki Konaka, \\ Yoshifumi Kadono, ${ }^{1}$ Yasuhide Kitagawa, ${ }^{1}$ Sotaro Miwa, ${ }^{1}$ Misako Kumaki, ${ }^{1}$ \\ Evan T. Keller, ${ }^{2}$ and Mikio Namiki ${ }^{1}$ \\ 'Department of Integrative CancerTherapy and Urology, Kanazawa University \\ Graduate School of Medical Sciences, Kanazawa, Ishikawa, Japan \\ ${ }^{2}$ Departments of Urology and Pathology, University of Michigan, Ann Arbor, Michigan
}

\begin{abstract}
BACKGROUND. The matricellular protein secreted protein acidic and rich in cysteine (SPARC) plays an important role on tumor metastasis and progression in several cancers. However, the roles of SPARC in prostate cancer $(\mathrm{PCa})$ remain unclear.

METHODS. To identify SPARC protein in prostate tissue, immunohistochemical analysis of SPARC was conducted using human prostate tissue microarray. To detect SPARC expression in prostate cancer (LNCaP, DU145, and PC-3) and stromal cells, RT-PCR, western blot analysis, and ELISA was conducted. To reveal the function of exogenous SPARC in PCa cells, AKT phosphorylation was confirmed by western blot analysis after coculture with stromal cells. Proliferation and migration of PCa cells were examined by addition of SPARC. The interaction between SPARC and integrin $\beta 1$ was confirmed by western blot analysis after immunoprecipitation.

RESULTS. SPARC protein was expressed well in normal tissue compared with PCa tissue. ELISA showed high secreted SPARC protein in normal prostate-derived stromal cell (PrSC) compared with PCa-derived stromal cell (PCaSC) and PCa. PCa cells cocultured with PrSC showed reduced AKT phosphorylation more than with PCaSC. PCa cells cocultured with PrSC whose SPARC was knocked-down restored AKT phosphorylation. Moreover, PCa cells treated with SPARC led to reduced AKT phosphorylation. Immunoprecipitation with SPARC revealed interaction of SPARC and integrin $\beta 1$ in PCa cells. Inhibited proliferation and migration of PCa cells by SPARC was restored by integrin $\beta 1$ neutralizing antibody.

CONCLUSIONS. Reduced SPARC secretion from stromal cells might affect PCa progression mediating through limiting AKT phosphorylation after interaction with integrin $\beta 1$.

Prostate 73: 1159-1170, 2013. (c) 2013 Wiley Periodicals, Inc.
\end{abstract}

KEY WORDS: $\quad$ prostate cancer; SPARC; stromal cells; integrin $\beta 1$

\section{INTRODUCTION}

Prostate cancer (PCa) is a common malignancy in men worldwide and the second leading cause of cancer related death among the male population of the United States [1]. It has been determined that advanced PCa cells usually metastasizes to bone [2] and lymph nodes [3]. Tumor metastasis and growth occur in the context of extracellular matrix (ECM) and require an interaction of malignant cells with various
Grant sponsor: Ministry of Education, Culture, Sport, Science, and Technology of Japan; Grant numbers: 23791747, 23390379.

All authors declare no conflict of interest.

*Correspondence to: Atsushi Mizokami, Department of Integrative Cancer Therapy and Urology, Kanazawa University Graduate School of Medical Sciences, 13-1 Takaramachi, Kanazawa, Ishikawa 920-8640, Japan. E-mail: mizokami@ med.kanazawa-u.ac.jp Received 11 February 2013; Accepted 26 February 2013 DOI 10.1002 / pros.22664

Published online 26 March 2013 in Wiley Online Library (wileyonlinelibrary.com). 
microenvironments [4,5]. As matricellular proteins in the ECM mediate the interactions between cell-cell and cell-extracellular environment, understanding the interaction of cancer cells with their microenvironment has emerged as an essential step.

Secreted protein acidic and rich in cysteine (SPARC)/osteonectin/BM-40 is a matricellular glycoprotein that plays instrumental roles during cell proliferation, immune response, migration, and cell differentiation modulating reversible interactions between cells and ECM [6]. Several proteinases, including matrix metalloproteinases (MMPs), release bioactive fragments from SPARC that also affect angiogenesis and cell behavior [7]. In tumorigenesis, SPARC interacts with an ECM and is associated with tumor cell growth, differentiation, metastasis and invasion [8-10]. A secreted glycoprotein, SPARC binds to several integral components of the ECM. Although high-affinity SPARC receptor has not been identified [11], numerous studies suggest that SPARC regulates integrin signaling and the ability of integrins to interact with structural components of the ECM $[12,13]$. Recent studies have shown that SPARC-knockout mice grow cancers faster than mice expressing SPARC $[14,15]$ and show accelerated wound healing [16,17]. SPARC acts not as a tumor suppressor but also as a promoter of invasiveness through integrin axis in melanoma, and was studied as a molecular marker, which represent a highly aggressive phenotype [18,19]. SPARC takes different contradictory actions depending on celltype and context showing contradictory effects on tumor progression.

The role of SPARC in PCa is also not fully understood yet. SPARC has been reported to be predominantly tumorigenic in PCa cells $[20,21]$. In contrast, recent studies with homozygous SPARC $\mathrm{KO} / \mathrm{TRAMP}$ model has been reported that SPARC was limiting for primary prostate tumorigenesis and progression [22]. Kapinas et al. [23] identified bone matrix-associated SPARC limited proliferation of $\mathrm{PCa}$ cells and increased their sensitivity to ionizing radiation. Since tumors are heterogeneous population, effects of SPARC on PCa cells are the results of a crosstalk between PCa cells and microenvironments.

In that respect, we aim to provide insight into how SPARC might affect PCa cells. We investigated how differentially expressed SPARC between normal prostate derived stromal cell (PrSC) and PCa-derived stromal cell (PCaSC) affect the progression of $\mathrm{PCa}$ cells. We also confirmed an interaction between SPARC and integrin $\beta 1$, which may define the signaling mechanism for migration and proliferation of PCa cells.

\section{MATERIALS ANDMETHODS}

\section{Immunohistochemistry of SPARC}

For tissue microarrays (TMAs), we purchased from Isu Abxis Co. Ltd. (South Korea) and Provitro (Berlin, Germany). The procedure for immunohistochemical staining (IHC) was performed using a Dako ChemMate ENVISION Kit/HRP(DAB)-universal kit (K5007) according to the manufacturer's protocol (Dako, Carpinteria, CA). After blocking endogenous peroxidase activity using 3\% hydrogen peroxide for $10 \mathrm{~min}$, the sections were incubated with rabbit monoclonal antibodies against SPARC (R\&D system) at a dilution of $5 \mu \mathrm{g} / 200 \mu \mathrm{l}$ at room temperature for $60 \mathrm{~min}$. After the primary antibodies reaction, sections were washed with PBS slowly and followed by peroxidase labeled secondary antibody (a mixture of rabbit and mouse antibodies) combined with dextranpolymers. Brownish staining for target proteins on tissue slides was developed using DAB within $5 \mathrm{~min}$, and counterstained with hematoxylin. Images were captured on microscope $\times 40$ and $\times 100$.

\section{Cell Lines, Reagents, and Transfections}

DU145, LNCaP (American Type Culture Collection, Manassas, VA) were cultured in Dulbecco's Modified Eagle's Medium (DMEM) supplemented with $1 \%$ penicillin/streptomycin (Invitrogen, Carlsbad, CA) and 5\% fetal bovine serum (FBS; SigmaAldrich, St. Louis, MO) and PC-3 (American Type Culture Collection) were cultured in RPMI1640-5\% FBS. Normal prostate-derived stromal cells, PrSC, commercially available (Cambrex, East Rutherford, NJ) were cultured using SCGM Bullet Kit (Cambrex). Human PCaSC were isolated from PCa tissue as described previously [24] and cultured in RPMI1640$10 \%$ FBS. Cell cultures were incubated at $37^{\circ} \mathrm{C}$ with $5 \% \mathrm{CO}_{2}$. For coculture, $0.4 \mu \mathrm{m}$ pore size transwell was used. PCa cells (LNCaP, DU145, and PC-3) were placed on the bottom of the lower chamber while PrSC and PCaSC were placed on the membrane of the upper chamber. The transwell prevents direct cell-cell interactions but allows the diffusion of soluble factors through the membrane. For treatment with SPARC (Osteonectin, Human platelets; Calbiochem, La Jolla, CA), all cells were serum-starved in medium containing $0.1 \%$ FBS for $12 \mathrm{hr}$, followed by incubation with SPARC or vehicle (media) for $24 \mathrm{hr}$. Cells were harvested for protein and mRNA detection. For blocking experiments, $10 \mu \mathrm{g} / \mathrm{ml}$ nonspecific IgG, integrin $\beta 1$-blocking antibody (Millipore, USA) was added to the media during SPARC treatment. 


\section{ReverseTranscription-PCR (RT-PCR)}

Total RNA was extracted from confluent monolayers of cells using an RNeasy Mini Kit (Qiagen, Hilden, Germany). Complementary DNA (cDNA) was made by reverse-transcription (RT) of $1 \mu \mathrm{g}$ of each total RNA using cDNA Synthesis Kit (Bio-Rad, USA). Each cDNA sample was amplified with ExTaq (Takara Bio, Japan). The oligonucleotide primer sets used for PCR analysis of cDNA were SPARC, 5'CGGGACTTCGAGAAGAACTA-3' (forward) and 5'AGACCTGTGACCTGGACAAT- $3^{\prime}$ (reverse), GAPD $\mathrm{H}, 5^{\prime}$-CCACCCATGGCAAATTCCATGGCA-3' (forward) and 5'-TCTAGACGGCAGGTCAGGTCCACC$3^{\prime}$ (reverse), Integrin $\alpha 1,5^{\prime}$-GTGGGCCAACAAAGAACACT-3' (forward) and 5'-TGGAAGCAGGCCCAAATATAG-3' (reverse), Integrin $\alpha 2,5^{\prime}$-GTTTT GAAAGGCGAGCAAAG-3' (forward) and $5^{\prime}$-GCTG TTGGCTAAAGGACTCG-3' (reverse), Integrin $\beta 1,5^{\prime}$ GGCTCTGCTTTGGACAGAAC-3' (forward) and $5^{\prime}$ ACCACGGAAACAAGGAAGTG-3' (reverse), Integrin 32 , 5-CACAAGCTGGCTGAAAACAA-3' (forward) and 5'-ATTGCTGCAGAAGGAGTCGT-3' (reverse). For SPARC, Integrin and GAPDH amplification, the PCR condition was $94^{\circ} \mathrm{C}, 3 \mathrm{~min}$ followed by 30 cycles of $94^{\circ} \mathrm{C}, 40 \mathrm{sec} ; 57^{\circ} \mathrm{C}, 30 \mathrm{sec} ; 72^{\circ} \mathrm{C}, 30 \mathrm{sec}$; and $72^{\circ} \mathrm{C}, 3 \mathrm{~min}$ final extension. The amplified PCR products were visualized using electrophoresis on a $1.5 \%$ agarose gel.

\section{Western Blot Analysis}

Cells were lysed in mammalian protein extraction buffer (Pierce, Rockford, IL), and total protein was extracted as described previously [25]. Equal amounts of protein were resolved on a $10 \%$ or $12.5 \%$ Ready Gel J (Bio-Rad, Hercules, CA), transferred onto a PVDF membrane (Invitrogen), and blocked with 5\% non-fat dry milk at room temperature. Membranes were probed overnight with primary antibodies against SPARC (Cell Signaling Technology, Beverly, MA), GAPDH (Novus Biologicals, Littleton, CO), AKT (Cell Signaling), P-AKT (Cell Signaling), SPARC (Cell signaling), and PARP (Cell signaling) followed by HRPconjugated secondary antibodies. An ECL system was used to detect chemiluminescent signals (SuperSignal West Pico Chemiluminescent Substrate; Pierce).

\section{Enzyme-Linked Immunosorbant Assay (ELISA)}

Cells $\left(4 \times 10^{5}\right.$ cells/well, six-well plates $)$ were stimulated with SPARC for $24 \mathrm{hr}$ and the amount of SPARC protein in cell culture media was determined by using commercially available SPARC ELISA kits (Takara Bio). The conventional ELISAs were prepared by coating the bottom of a 96-well plate with capture antibodies. Cell culture media was incubated for one $\mathrm{h}$ in antibody coated plate then washed four times with TBST. Equal amounts of substrate solution were added to each well and incubated for $15 \mathrm{~min}$ at room temperature. After adding stop solution, absorbance readings were made at $450 \mathrm{~nm}$, using a 96-well plate spectrophotometer.

\section{Cytokine Antibody Array}

Secreted SPARC was analyzed with a cytokine antibody array by using a RayBio cytokine antibody array kit (RayBiotech, Inc., Norcross, GA), according to the manufacturer's instructions. Supernatants of cells were incubated with blocked membranes and then incubate with biotinylated detection antibody cocktail and HRP-conjugated streptavidin. Signal intensities were quantified directly with a chemiluminescence imaging system and Image J (NIH, USA) software.

\section{RNA Interference Analysis}

The specific SPARC interfering RNAs (siRNA) sequences were designed by Invitrogen. SPARC target siRNA sequence was 5'-UAGAAUUGCAACAGCUUGUCCUUCC-3'. Non-target siRNA (NT siRNA) were purchased from Invitrogen. For SPARC knockdown in PrSC, transfection experiments were performed using Lipofectamine RNAiMAX Reagent (Invitrogen) according to the manufacturer's protocol (Invitrogen). Briefly, cells were transfected with of 5, 10, and 20 nM SPARC siRNA or $20 \mathrm{nM} \mathrm{NT}$ siRNA for $24 \mathrm{hr}$. After $6 \mathrm{hr}$ of transfection, complete medium was added and cells were cultured for another 12 or $24 \mathrm{hr}$. At the end of the culture period, total RNA were exacted or the cells were transferred to transwell for coculture.

\section{Immunoprecipitation (IP)}

After finishing various treatments, cells were lysed in mammalian protein extraction buffer (Pierce) as described under western blot procedure. Immunoprecipitation were performed using Catch and release IP reagents (Abcam, MA) according to the manufacturer's protocol. Briefly, total proteins were quantified according to the method of Bradford, and equal amounts of protein $(500 \mu \mathrm{g})$ were mixed with $2 \mu \mathrm{g}$ of rabbit monoclonal antibodies against SPARC (Cell Signaling) and Affinity ligand. After providing a final volume $500 \mu \mathrm{l}$, the mixtures were incubated on a rotor mixer at room temperature for $30 \mathrm{~min}$. Unbounded non-specific proteins were washed with the wash buffer and immunocomplexes with Antibody Capture Affinity Ligand (ACAL) were left. From the complex, eluted proteins were subjected to western blot 
analysis with integrin $\beta 1$ antibody (Cell signaling) and for normalization of rabbit monoclonal antibodies against SPARC (Cell Signaling), anti-rabbit HRPlinked antibody (Cell Signaling) was used.

\section{Cell Proliferation Assays}

Cell proliferation was determined using a quick cell proliferation assay kit (Abchem) according to the manufacturer's instructions. Cells $\left(3 \times 10^{4} /\right.$ well $)$ were plated in 96-well microtiter plate in a final volume of $100 \mu \mathrm{l} /$ well culture medium in absence or presence of SPARC $(\mu \mathrm{g} / \mathrm{ml})$ integrin $\beta 1$-blocking antibody $(10 \mu \mathrm{g} / \mathrm{ml})$. After 12, 24, 36, and $72 \mathrm{hr}, 10 \mu \mathrm{l} /$ well WST-1/ECS solution was added and incubated $4 \mathrm{hr}$ in standard culture condition $\left(37^{\circ} \mathrm{C}\right.$ with $5 \%$ $\mathrm{CO}_{2}$ ). Plate was shaken thoroughly for $1 \mathrm{~min}$ on a shaker. The absorbance of each well was measured at $450 \mathrm{~nm}$ with a microtiter plate reader.

\section{Migration Assay}

In vitro wound-healing assay was performed as previously described [25]. Cells were incubated in culture medium containing with $1 \%$ penicillin/streptomycin and 5\% FBS in presence or absence of $0.5 \mu \mathrm{g} / \mathrm{ml}$ SPARC. Wound healing was visualized with photographs by microscope. Cell migration assay using a transwell were performed in migration and invasion chambers according to the manufacturer's instructions (Cell Biolabs, Inc., CA). Before assay, cells were serum-deprived for $24 \mathrm{hr}$, and cells were placed into upper chamber in serum-free medium. Medium supplemented with 5\% FBS was placed in the lower chamber with SPARC $(\mu \mathrm{g} / \mathrm{ml})$ or isotype control and integrin $\beta 1$-blocking antibody $(10 \mu \mathrm{g} /$ $\mathrm{ml}$ ), respectively. After incubation, cells that had migrated to the lower surface of the filters were stained and quantified by colorimetric reading at $560 \mathrm{~nm}$.

\section{Statistical Analysis}

All data are presented as mean $\pm S D$, and statistical significance was determined by using the Prism 4.0 software. The $\chi^{2}$ test was utilized to assess the significance between different proportions. Analysis of continuous variables between different groups was assessed by one-way analysis of variance followed by Fisher's protected least significant difference test. Differences were considered to be statistically significant. Relative amount values were expressed as means $\pm \mathrm{SD}$ from Three replicate experiments. ${ }^{*}$ and ${ }^{* *}$ represent significant difference $P<0.05$, and $P<0.01$, respectively. Kruskal-Wallis test was used to determine the statistical significance of differences in IHC staining of tissue microarray.

\section{RESULTS}

\section{Distribution of SPARC Between Human Prostate Cancer and Normal Prostate}

To investigate the effect of SPARC on human $\mathrm{PCa}$, we first examined the existence of SPARC protein in human prostate. As shown in (Fig. 1A-H), immunohistochemistry using tissue microarrays revealed that SPARC was expressed in $87 \%$ normal prostate tissues $(28 / 32)$ and in $9 \%$ of the tumor tissues (4/64; Table I). Normal prostates cells showed strong intensity of SPARC expression compared with prostate caner tissue $(P<0.001)$. Strong staining of SPARC in normal stroma was also observed compared with PCa stroma. We could not observe significant difference in the intensity of SPARC staining among the level of Gleason score statistically.

\section{Differential Expression of SPARC in Prostate Cancer Cell Lines and Prostate Derived Stromal Cell Lines}

SPARC is a highly conserved, multifunctional protein that regulates various cell in different ways [10]. To determine the roles of SPARC from prostate stromal cells on PCa cells, we first examined the expression of SPARC mRNA and protein in LNCaP, DU145, and PC-3 cells, PCaSC-5, 8 (PCa-derived stromal cells), and PrSC (normal prostate- derived stromal cells; Fig. 2A,B). Both mRNA and protein level of SPARC (42 kDa) was higher in PCaSC-5, -8, and PrSC) than PCa cells (LNCaP, DU145, and PC3). Moreover, western blot analysis revealed higher expression of SPARC protein in PrSC than PCaSCs. SPARC has been reported as secreted noncollagenous glycoprotein that closely associated with an ECM [6]. We also examined secreted SPARC in medium from PCa cells, PCaSCs, and PrSC by ELISA (Fig. 2C). Secreted SPARC level from stromal cells was relatively high compared with three kinds of PCa cells. Furthermore, the amount of secreted exogenous SPARC from PrSC was 1.8-2.4 times higher than other PCa-derived stromal cells (PCaSC-5, -6, $-7,-8)$ and 6.8-11.3 times higher than PCa cells (LNCaP, DU145, and PC-3). To evaluate SPARC protein expression levels of cytoplasm, we performed cytokine assay using anti-cytokine specific membrane and compared the level of secreted cytokines from normal prostate stromal cells (PrSC) and PCaderived stromal cells (PCaSC-5; Fig. 2D). This result was coincident well with ELISA: the lower expression of SPARC in PCaSC-5 was detected compared with normal prostate PrSC. Therefore, we investigated the effect of diminished SPARC expression in PCa stromal cells on PCa cells. 

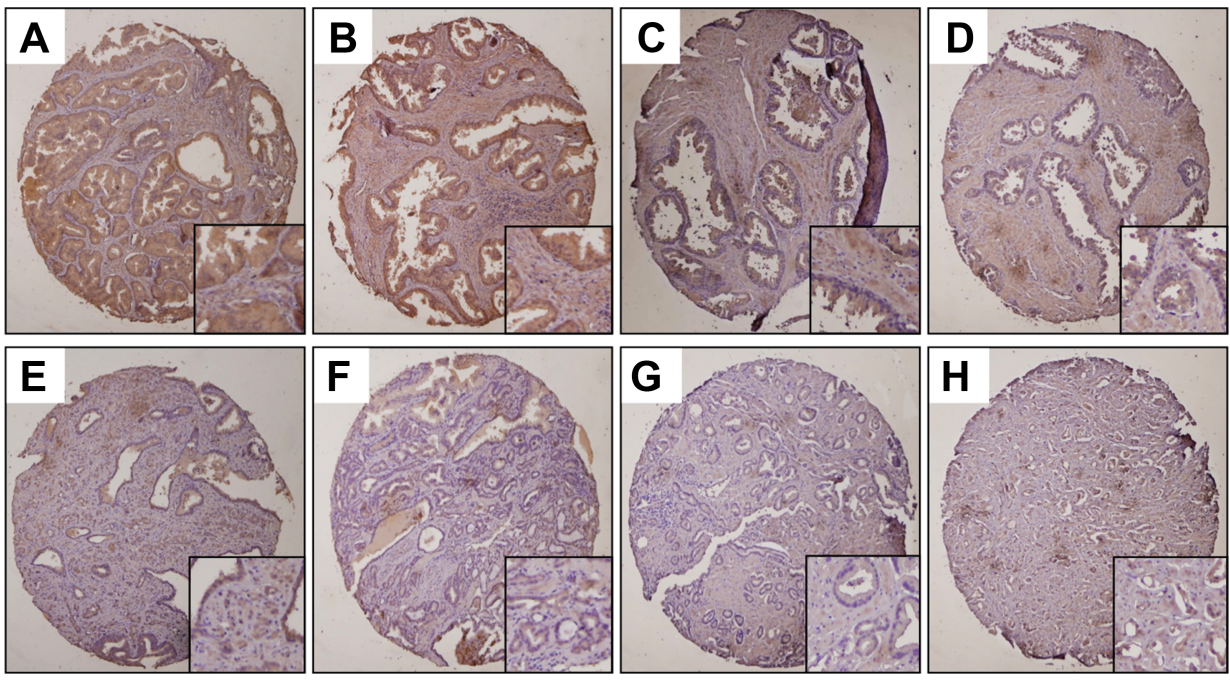

Fig. I. Immunohistochemical staining of SPARC on prostate tissue. Commercial PCa tissue microarray (TMA) slides (A-H) were deparaffinized in xylene and rehydrated in graded alcohols and processed as described method. TMAs with 96 specimens and tissue sections were immunostained with SPARC antibody. Representative examples of photomicrographs are showing SPARC expression in the non-neoplastic prostate and PCa. A: non-neoplastic from E. B: non-neoplastic from F.C: non-neoplastic from G. D: non-neoplastic from H. E: Gleason score 7 . F: Gleason score 7.G: Gleason score 8. H: Gleason score 9 (original magnification $\times 40$ and $\times 100$ ).

\section{Exogenous SPARC Reduces AKT Phosphorylation}

Since stromal cells, especially normal prostate stromal cells (PrSC) secreted SPARC well compared with PCaSC, we investigated the effect of exogenous SPARC secreted from stromal cells on PCa cells. We first analyzed whether exogenous SPARC induces any change in AKT signal that provides a major therapeutic opportunity in prostate disease [26]. Western blot analysis revealed that exogenous SPARC reduces AKT phosphorylation in a dose-dependent manner in LNCaP, DU145, and PC-3 cells (Fig. 3A). We also performed coculture of $\mathrm{PCa}$ cells with stromal cells that secrets higher level of SPARC protein (Fig. 3B). Phosphorylation of AKT was decreased in all PCa cells by coculture with stromal cells in accordance with secreted level of SPARC. Many soluble factors from stromal cells may affect phosphorylation of AKT in PCa cells. In order to confirm reduced phosphorylation in $\mathrm{PCa}$ cells is due to secreted SPARC from stromal cells, we performed knockdown of SPARC in PrSC using small interfering RNA. Knockdown of SPARC by siSPARC repressed the expression level of SPARC MRNA and secreted SPARC protein in medium in dose-dependent manner (Fig. 3C). Then coculture of PCa cells with PrSC transfected with siSPARC reduced AKT phosphorylation in all PCa cells (Fig. 3D).

\section{Exogenous SPARC-Integrin $\beta$ I Interaction Reduces AKT Phosphorylation}

Goal et al. has shown that that tumor cells express an abnormal integrin repertoire and surrounded by a markedly aberrant ECM [27]. To reveal the

TABLE I. Immunohistochemistry of SPARAC on ProstateTissue Microarray

\begin{tabular}{|c|c|c|c|c|c|}
\hline \multirow[b]{2}{*}{ Clinicopathological features } & \multicolumn{3}{|c|}{ SPARC expression } & \multirow[b]{2}{*}{ Total number } & \multirow[b]{2}{*}{$P$-value } \\
\hline & $(-)$ & $(+)$ & $(++)$ & & \\
\hline Normal & 1 & 2 & 19 & 22 & \\
\hline PIN & 2 & 3 & 5 & 10 & 0.001 \\
\hline \multicolumn{6}{|l|}{ Gleason score } \\
\hline 5,6 & 7 & 2 & 1 & 10 & 0.001 \\
\hline 7 & 28 & 2 & 0 & 30 & 0.001 \\
\hline $8,9,10$ & 23 & 1 & 0 & 24 & 0.001 \\
\hline Total number & 61 & 10 & 25 & 96 & \\
\hline
\end{tabular}



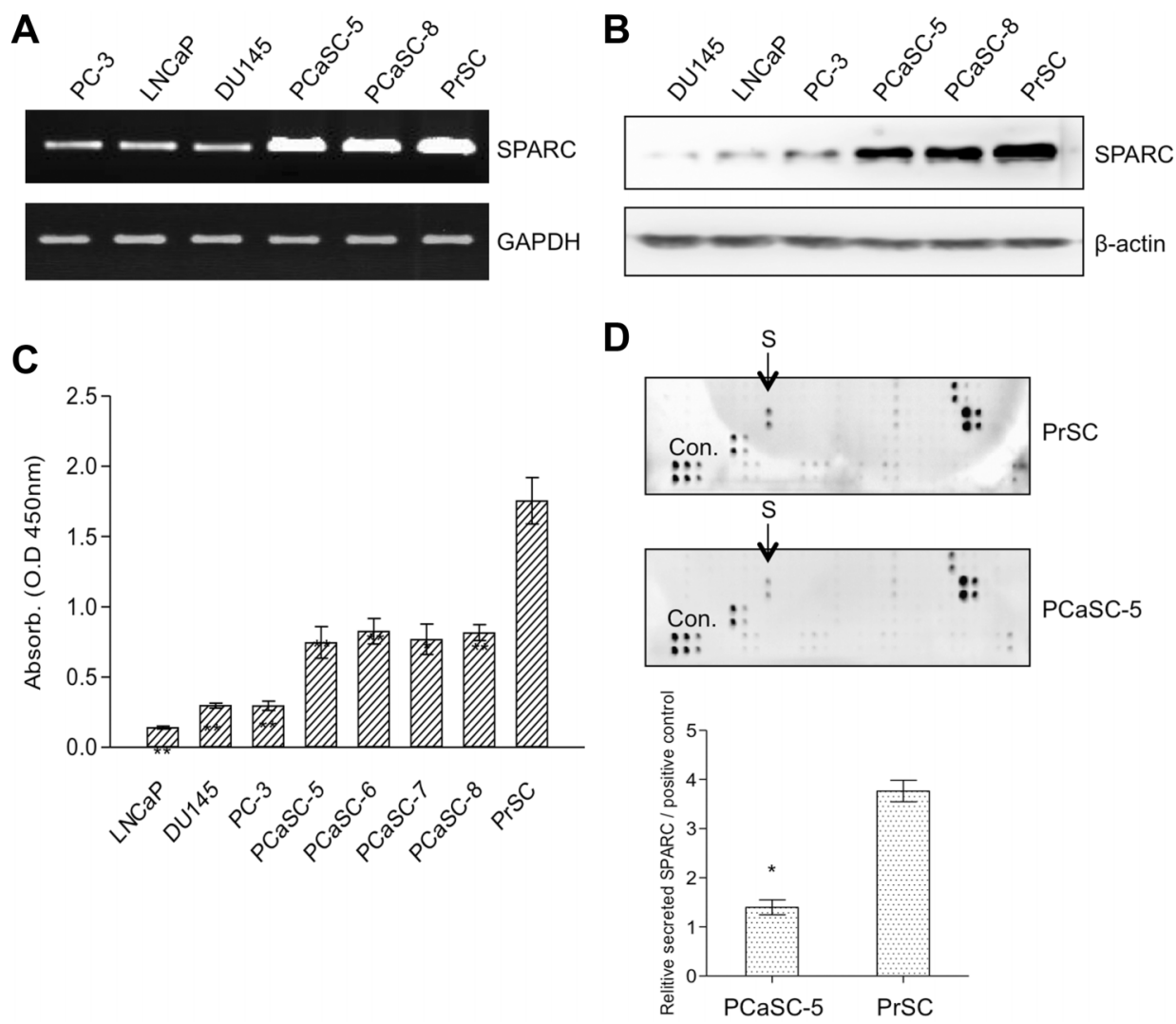

Fig. 2. Expression level of SPARC in PCa cells, PrSC, and PCaSCs. A: Expression levels of SPARC mRNA were measured in PCa cell lines (LNCaP, DUI45, and PC-3) and stromal cell lines (PCaSC-5, PCaSC-8, PrSC) by RT-PCR. B: Whole cell lysate from each cells were also subjected toWestern blot analysis and normalized as a ratio using $\beta$-actin. $C$ : Each cell $\left(4 \times 10^{5}\right)$ was cultured in serum-free medium for 36 hr and SPARC protein concentrations in the medium were measured by ELISA assay. OD values obtained by ELISA reader at $450 \mathrm{~nm}$ are expressed as means \pm SD from four replicate experiments. Cells $\left(I \times 10^{6}\right.$ cells $)$ were cultured with $0.2 \% \mathrm{FBS}$ for 2 days and the supernates were incubated with commercially available array membrane. D: Comparison of Secreted SPARC in PrSC and PCaSC-5. Images were collected using a chemiluminescence imaging system after cytokine array. S represents secreted SPARC (top). The data on the bottom represents relative amount of secreted SPARC.

relationship between exogenous SPARC and integrins, the expression level of integrin mRNA in PCa cells treated with SPARC for 2 days was examined using quantitative RT-PCR (Fig. 4A). Regardless of a dose of SPARC, the expression level of integrin $\alpha 1$, $\alpha 2$, and $\beta 2$ mRNA was constant. However, the expression level of only integrin $\beta 1$ mRNA was increased in a dose-dependent manner. To confirm the direct interaction between exogenous SPARC and integrin $\beta 1$, lysate from LNCaP, DU145, and PC-3 cells that were treated with exogenous SPARC were immunoprecipiated with anti-SPARC antibodies and were subsequently probed for anti-integrin. Although no interaction was detected when immunoprecipitation was probed for anti-integin $\alpha 1, \alpha 2$, and $\beta 2$ (data not shown), exogenous SPARC interacted with integrin $\beta 1$ (Fig. 4B). To further verify the apparent interaction between SPARC and integrin $\beta 1$, we pretreated integrin $\beta 1$-blocking antibody and nonspecific isotype control antibody in LNCaP, DU145, and PC-3 cells, and then treated with SPARC for 2 days. The interaction between integrin $\beta 1$ and exogenous SPARC was diminished by integrin $\beta 1$-blocking antibody. Furthermore, after blocking the interaction reduced AKT phosphorylation by exogenous SPARC was recovered (Fig. 4C), suggesting that exogenous SPARC directly binds to integrin $\beta 1$ and affects AKT signaling.

\section{Exogenous SPARC Decreases Prostate Cancer Cells Proliferation}

We analyzed the effect of exogenous SPARC on cell proliferation (Fig. 5A). The proliferation rates of LNCaP, DU145, and PC-3 cells treated with $1 \mu \mathrm{g} / \mathrm{ml}$ SPARC were decreased compared with vehicle. To determine whether inhibition of cell proliferation by 
A
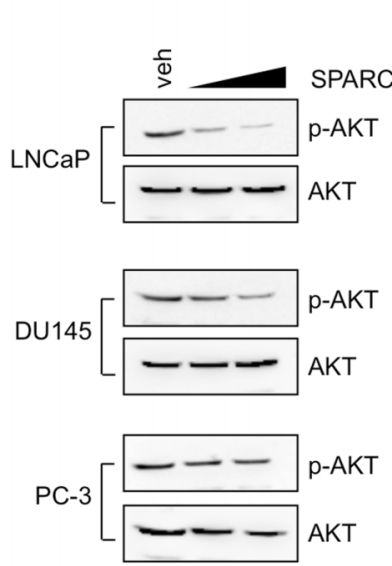

B
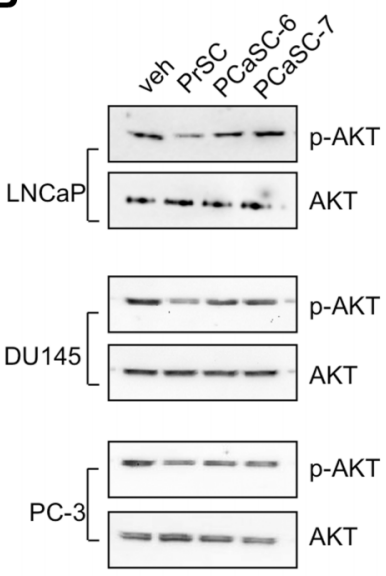

C
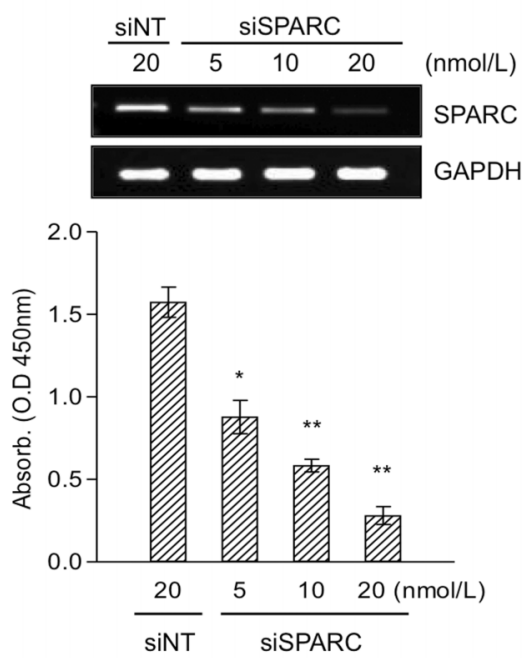
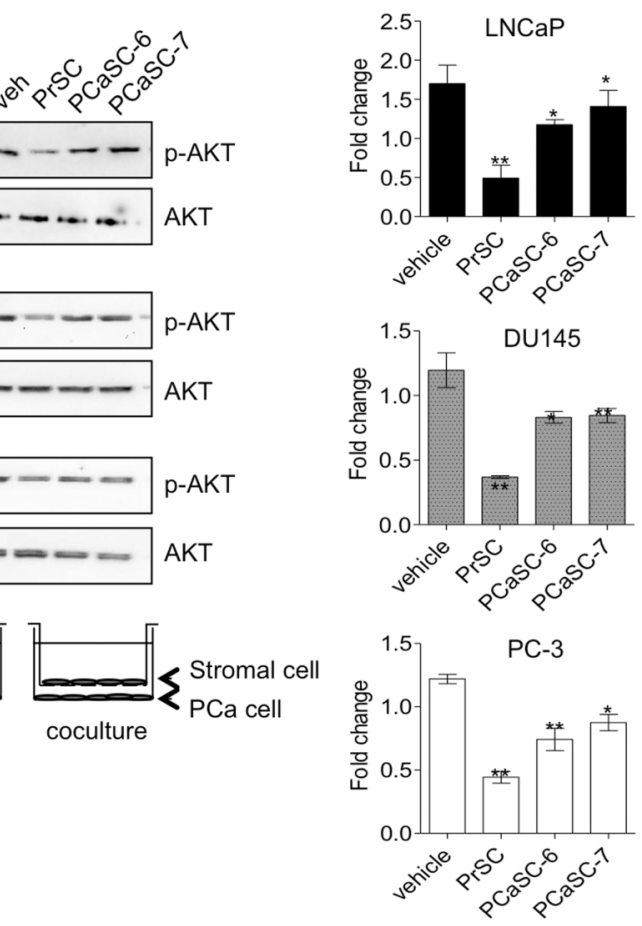

D

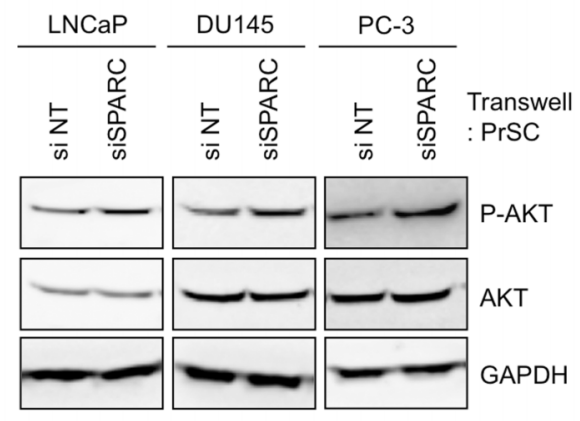

Fig. 3. Inactivation of AKT by exogenous SPARC. A: After $L N C a P$, DUI45, and PC- 3 cells $\left(4 \times 10^{5}\right)$ were treated with vehicle (medium) or $0.5,1.0 \mu \mathrm{g} / \mathrm{ml} \mathrm{SPARC}$ for 2 days, whole cell lysate from each sample was also subjected to Western blot analysis. B: LNCaP, DUI45, and PC-3 cells were cocultured with vehicle, PrSC, PCaSC-6, and PCaSC-7 for $48 \mathrm{hr}$ in a transwell chamber as illustrated transwell coculture systems. The cell lysates from PCa cells were subjected to western blot analysis with anti-phospho-AKTand anti-AKTantibody (Left panel). Right panel represents relative changes of phospho-AKTexpression. C: Knockdown of SPARC expression in PrSC by SPARC siRNA transfection. Expression of SPARC mRNA was detected by RT-PCR (Top). After transfection of SPARC siRNA $\left(4 \times 10^{5}\right.$ cells), SPARC concentrations in the medium were measured by ELISA (Bottom). D: LNCaP, DUI45, and PC-3 were cocultured with $20 \mathrm{nmol} / \mathrm{L} \mathrm{SPARC}$ siRNA transfected PrSC for $48 \mathrm{hr}$ in a transwell chamber. The cell lysates with an equal amount of proteins in cells were subjected to western blot with anti-phospho-AKTand antiAKTantibody.

SPARC is resulted from apoptosis, PCa cells were treated with $1.0 \mu \mathrm{g} / \mathrm{ml}$ SPARC for 2 days, and then stained with DAPI to confirm apoptosis. However, staining of nuclei by DAPI did not detect chromatin condensation that shows apoptosis although total number of cells nuclei was decreased by $1.0 \mu \mathrm{g} / \mathrm{ml}$ SPARC substantially compared with vehicle (data not shown). We also assessed the expression of apoptosis- related protein, PARP, and tried to detect apoptosis in PCa cells by apoptosis assay, measures the levels of soluble caspase-cleaved fragments, however, similarly there were no apoptotic change by exogenous SPARC (data not shown). Since we confirmed that total number of cells was decreased by exogenous SPARC with DAPI stain, we analyzed the effects of exogenous SPRAC on tumor growth using 

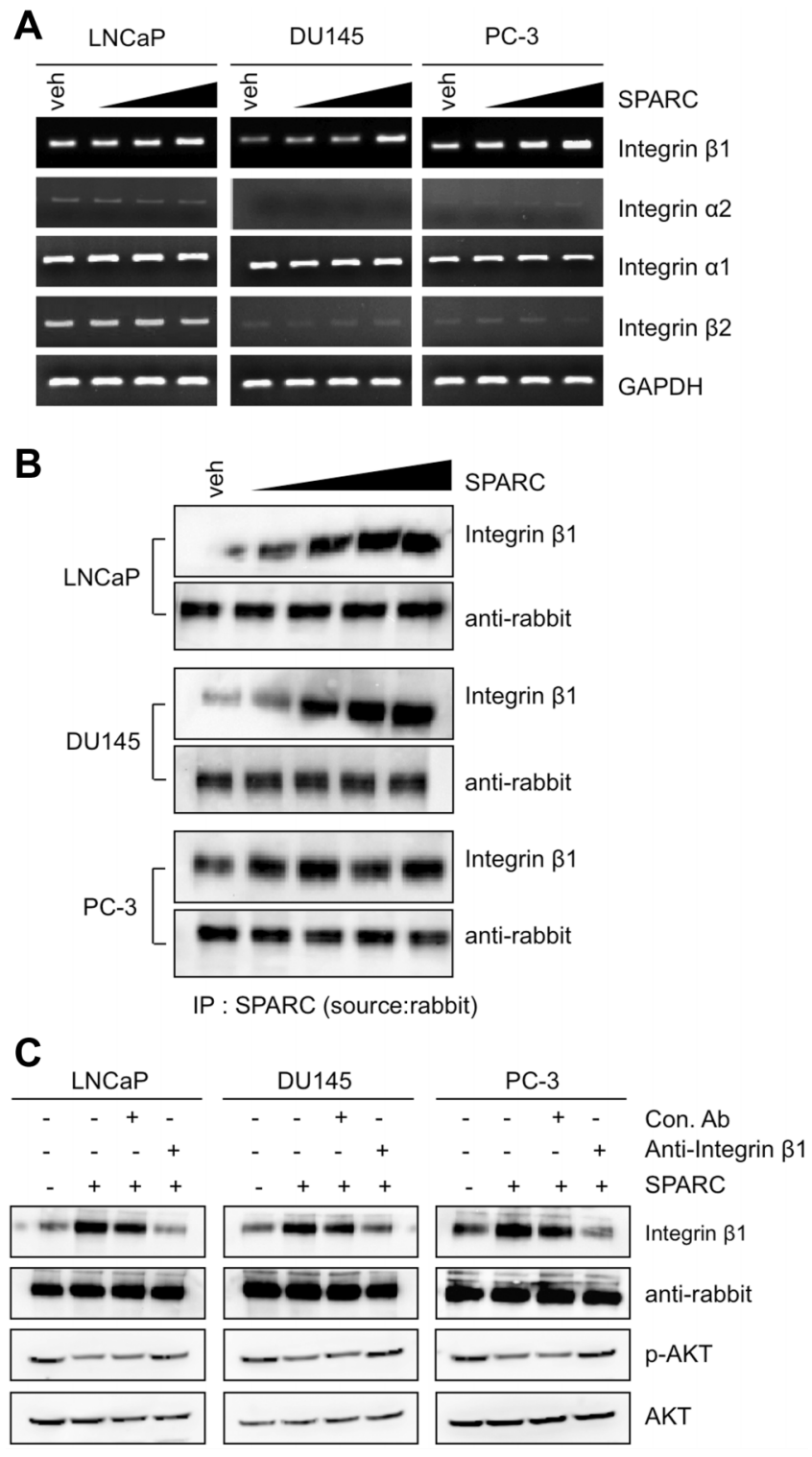

Fig. 4. Interaction of SPARC with integrin $\beta$ I. A: After $L N C a P$, DUI45, and PC- 3 cells $\left(4 \times 10^{5}\right)$ were treated with vehicle or $0.5,1.0$, and $2.0 \mu \mathrm{g} / \mathrm{ml} \mathrm{SPARC}$ for 2 days, the expression levels of integrin $\alpha \mathrm{l}$, $\alpha 2, \beta 1$, and $\beta 2$ mRNA were measured by RT-PCR. B: After cells were treated with $0,0.5,1.0,1.5$, and $2.0 \mu \mathrm{g} / \mathrm{ml}$ SPARC for 2 days, whole cell lysate from each sample were subjected to immunoprecipitation with anti-SPARC (source: rabbit) and anti-integrin $\beta$ I. Total protein used for immunoprecipitation was confirmed with an anti-rabbit antibody as precipitated anti-SPARC antibody source was rabbit. C: Cells were treated with $1.0 \mu \mathrm{g} / \mathrm{ml} \mathrm{SPARC}$ for 2 days in presence or absence of an isotype control or integrin $\beta \mathrm{I}$-blocking antibody $(10 \mu \mathrm{g} / \mathrm{ml})$. Immunoprecipitation was conducted with anti-SPARC and the precipitated proteins revealed with and antiintegrin $\beta$ antibodies. Whole cell lysate from each sample was also subjected to western blot analysis with anti-phospho-AKT and anti-AKTantibody. proliferation assay kit (Fig. 5A). The proliferation rates of three kinds of PCa cells treated with $1 \mu \mathrm{g} / \mathrm{ml}$ SPARC were decreased compared with vehicle. To determine whether the roles of exogenous SPARC in PCa cell proliferation depends on interaction with integrin $\beta 1$, cells were cultured for 12 and $72 \mathrm{hr}$ with or without integrin $\beta 1$-blocking antibody, nonspecific isotype control antibody and $1.0 \mu \mathrm{g} / \mathrm{ml}$ SPARC and then assessed to proliferation assay (Fig. 5B). The inhibited proliferation of PCa cells by treatment with SPARC was recovered by addition of integrin $\beta 1$ blocking antibody, suggesting that anti-proliferative effect of exogenous SPARC is mediated through integrin $\beta 1$.

\section{Exogenous SPARC Decreases Prostate Cancer Cells Migration}

To determine the effect of exogenous SPARC on migration in LNCaP, DU145, and PC-3 cells were assessed using the wound healing assay (Fig. 6A). One microgram per milliliter SPARC caused inhibition of cell migration in all three kinds of PCa cells. To further confirm this result, we performed the cell migration assay in the presence of the exogenous SPARC using a transwel chamber. As shown in Figure 6B, cell migration was also significantly decreased in the presence of $1 \mu \mathrm{g} / \mathrm{ml}$ SPARC. We also analyzed whether interaction between exogenous SPARC and integrin $\beta 1$ affects migration in PCa cells. After cells treated with $1.0 \mu \mathrm{g} / \mathrm{ml}$ SPARC were cultured with integrin $\beta 1$-blocking antibody or non-specific isotype control antibody for $48 \mathrm{hr}$, migration of PCa cells were assessed. As shown in Figure 6C, migration inhibited by treatment with SPARC in all PCa cells was recovered by addition of integrin $\beta 1$-blocking antibody. These results suggested that exogenous SPARC repressed migration of PCa cells mediated through integrin $\beta 1$.

\section{DISCUSSION}

Several studies have investigated that local changes in the physical properties of the matrix-associated factors from stromal cells might potentially lead to cancer cell progression [28,29]. Exogenous SPARC, one of the matrix-associated factors, has been reported to reduce the cell growth in ovarian cancer, neuroblastoma, and colorectal cancer $[8,30,31]$.

Our approach was to confirm how extracelluar matrix SPARC affects PCa progression. It is known that SPARC plays important roles in development and the control of proliferation and migration with complex biological effects that are cell and tumor type specific [10]. In PCa, although Jacob et al. reported SPARC as a predominantly protumorigenic protein [21], several 

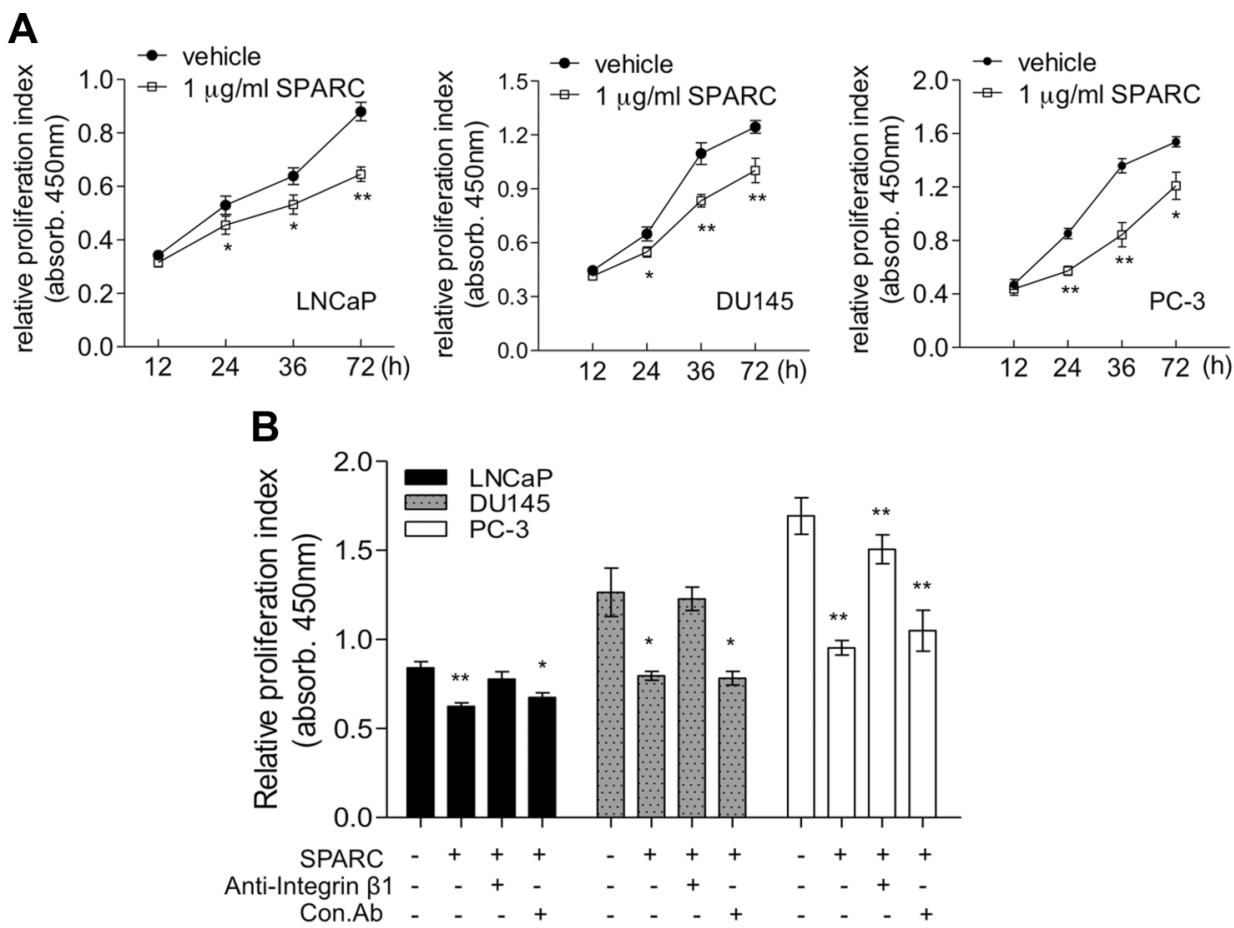

Fig. 5. Effect of exogenous SPARC on proliferation of prostate cancer cells. A: LNCaP, DUI45, and PC-3 cells $\left(3 \times 10^{4} /\right.$ well) were cultured with vehicle (media) or I $\mu \mathrm{g} / \mathrm{ml}$ SPARC in $5 \%$ FBS-containing medium for 12, 24, 36, and $72 \mathrm{hr}$. Cell proliferation was determined with a colorimetric WST-I/ECS assay. Experiments were conducted with three experimental replicates. B: Cells $\left(3 \times 10^{4} /\right.$ well $)$ were treated with $1.0 \mu \mathrm{g} / \mathrm{ml}$ SPARC for $72 \mathrm{hr}$ in presence or absence of an isotype control or integrin $\beta \mathrm{I}$-blocking antibody $(10 \mu \mathrm{g} / \mathrm{ml})$.

groups reported that SPARC down-regulated the proliferation and invasion of PCa cells [22,23,32], suggesting that SPARC can become the useful immunohistochemical biomarker of PCa. Of interest, normal prostate-derived stromal cells expressed high level of SPARC compared with PCa cells. Furthermore, the amount of secreted exogenous SPARC in normal prostate derived stromal cells (PrSC) was also 1.8-2.4 times higher than PCa-derived stromal cells (PCaSC-5, -6, -7, -8). Moreover, we demonstrated that exogenous SPARC suppresses cell proliferation and migration of three kinds of PCa cells (LNCaP, DU145, and PC-3). Our data support the concept that gradually diminished exogenous SPARC from PCaSC may affect $\mathrm{PCa}$ progression. It still remains unclear why the level of SPARC secretion from PCaSC is diminished compared with normal PrSC. Some factor from PCa cells may influence stromal cells to diminish a secretion of SPARC as well as stromal cells influencing PCa cells (Fig. 7).

Our data demonstrated that high expression of SPARC in stromal cells was correlated with suppression of AKT phosphorylation. PI3K/AKT signaling is critical to $\mathrm{PCa}$ cell survival and proliferation. Activated AKT translocates to the cytoplasm and nucleus and activates downstream targets involved in survival, proliferation, cell cycle progression, growth, migration $[33,34]$. To our knowledge, this is the first report that exogenous SPARC from stromal cells down-regulates AKT phosphorylation in PCa cells. Several previous reports associated with glioma and neuroblastoma showed that SPARC inhibits cancer cell proliferation through PTEN (phosphatase and tensin homolog deleted on chromosome 10) and AKT mediated signaling pathway. Thomas et al. reported that SPARC overexpression in glioma increased the tumor-suppressing potential of PTEN both in vitro and in vivo $[35,36]$. We further need to reveal whether exogenous SPARC-induced AKT dephosphorylation also regulate PTEN-related signaling pathway in $\mathrm{PCa}$ cells.

In the present study, we did not detect significant differences in mRNA expression of integrin $\alpha 1, \alpha 2$, and $\beta 2$ in PCa cells by exogenous SPARC. However, integrin $\beta 1$ mRNA expression was increased by exogenous SPARC. Although a number of studies have investigated the roles of integrin $\beta 1$, both up-regulation and down-regulation of integrin $\beta 1$ expression were reported during progression of prostate cancer $[37,38]$. However, dramatically reduced integrin $\beta 1$ expression was observed in PCa cells $[39,40]$ and Moran-Jones et al. [41] has shown that integrin $\beta 1$ 

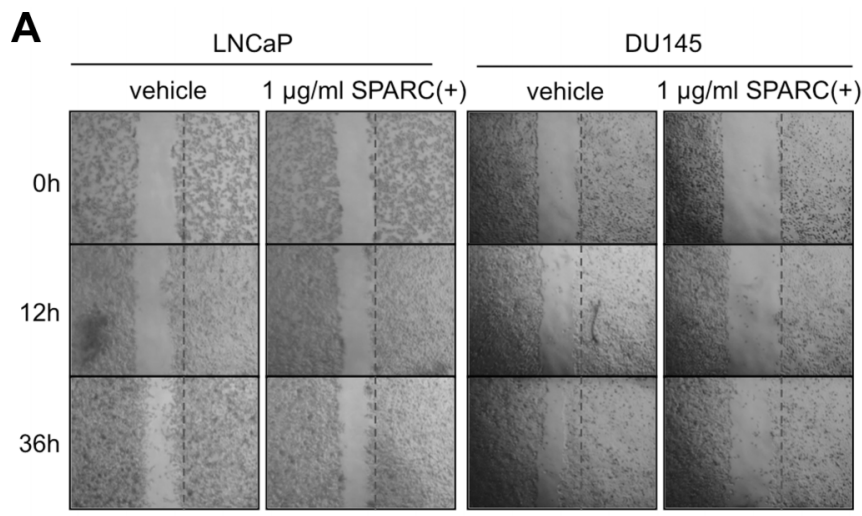

$\frac{\mathrm{PC}-3}{\text { vehicle } \quad 1 \mu \mathrm{g} / \mathrm{ml} \operatorname{SPARC}(+)}$

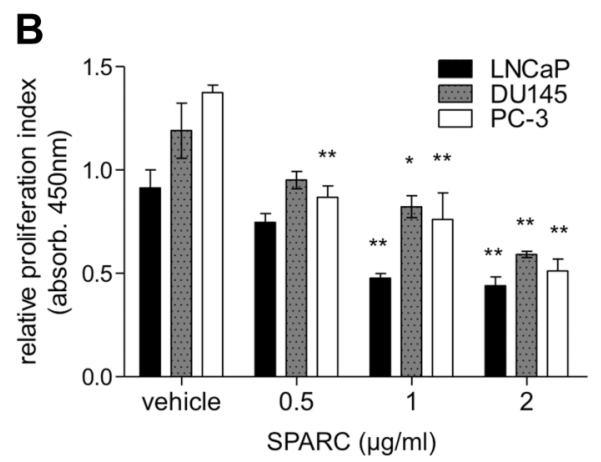

C

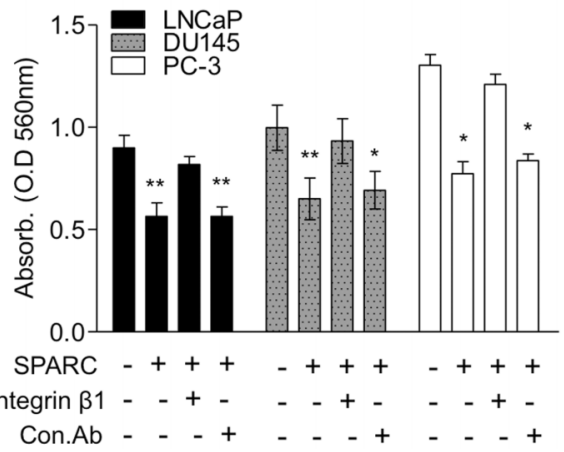

Fig. 6. Effect of exogenous SPARC on migration of prostate cancer cells. A: Representative photographs of migrated cells that received either control treatment or exogenous SPARC. Cells were wounded and then treated with vehicle (media) or I $\mu \mathrm{g} / \mathrm{ml}$ SPARC in 5\% FBS-containing medium. Images are taken immediately after scratching the cultures $(0 \mathrm{hr}), 12$, and $36 \mathrm{hr}$ later (original magnification, $\times 40)$. B: LNCaP, DUI45, and PC-3 cells were cultured under vehicle or $0.5,1.0$, and $2.0 \mu \mathrm{g} / \mathrm{ml} \mathrm{SPARC}$ conditions for 2 days. The cells were incubated on the $8 \mu \mathrm{m}$ pore polycarbonate membrane in a transwell. C: Cells were treated with $1.0 \mu \mathrm{g} / \mathrm{ml} \mathrm{SPARC}$ for 2 days in presence or absence of an isotype control or integrin $\beta \mathrm{I}$-blocking antibody $(10 \mu \mathrm{g} / \mathrm{ml})$. Cell migration was assessed by transwell migration assay.

regulated normal prostate development and its loss was associated with increased rates of prostate tumor progression [25]. Our results presented here are coincident with these ideas. Integrin $\beta 1$ by exogenous SPARC further adds to our understanding how

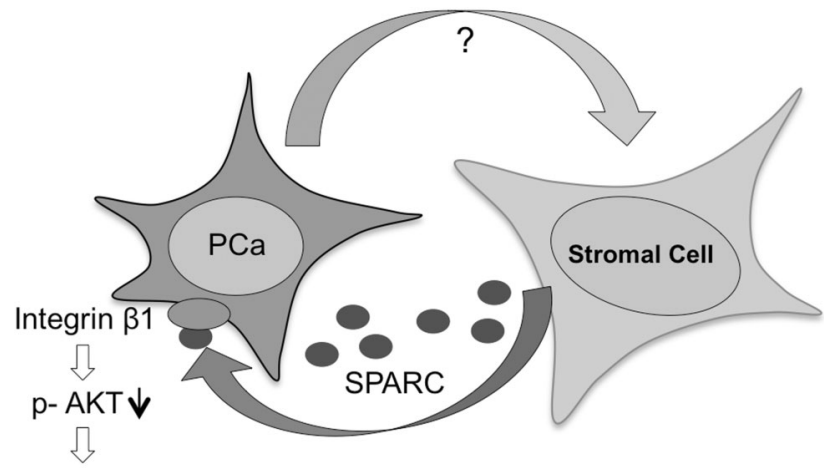

PCa cells growth \& migration $\downarrow \downarrow$

Fig. 7. Function of SPARC on prostate cancer. Mechanism of how exogenous SPARC from stromal cells effect on PCa cells growth and migration. integrin $\beta 1$ can repress tumor progression. Moreover, our data provide the first indication of the interaction between exogenous SPARC and integrin $\beta 1$ in PCa. We also confirmed that blocking the direct interaction of SPARC-integrin $\beta 1$ by integrin $\beta 1$-neutralizing antibody prevented SPARC from inhibiting proliferation and migration of PCa cells. These findings indicated the possibility that integrin $\beta 1$ played an important role as a receptor through direct interaction with SPARC. SPARC-integrin complex has studied in some types of cancers, and SPARC-integrin $\beta 1$ interaction was detected in lens epithelial cells (LEC) and astrocytes [42,43]. As a result of ours, integrin $\beta 1$ could be an important bridge signaling between exogenous SPARC and PCa cells that regulates proliferation and migration of PCa.

Our study suggests that exogenous SPARC interacted with integrin $\beta 1$ in PCa cells and induced suppression of AKT phosphorylation. Moreover, the interaction suppressed proliferation and migration of PCa cells (Fig. 7). Since normal prostate-derived stromal cells secrets high level of SPARC compared with 
PCa-derived stromal cells, loss of exogenous SPARC may has been linked to enhanced proliferation and migration of PCa cells. Therefore, exogenous SPARC and integrin $\beta 1$ provides potential therapeutic strategies to suppress PCa progression by maintaining the level of exogenous SPARC and/or by controlling the expression, availability and affinity of integrin $\beta 1$ as a receptor of exogenous SPARC. Understanding the mechanism of SPARC from microenvironment and integrin $\beta 1$ in progression of PCa cells may be useful as diagnostic approaches and therapeutic indicators.

\section{ACKNOWLEDGMENTS}

We thank Y. Kawabuchi for skilled technical assistance (Kanazawa University).

\section{REFERENCES}

1. Siegel R, Naishadham D, Jemal A. Cancer statistics, 2013. CA Cancer J Clin 2013;63(1):11-30.

2. Logothetis CJ, Lin SH. Osteoblasts in prostate cancer metastasis to bone. Nat Rev Cancer 2005;5(1):21-28.

3. Vanni AJ, Moinzadeh A. Lymphadenectomy in minimally invasive urologic oncology. Curr Opin Urol 2008;18(2):163166.

4. Radinsky R, Fidler IJ. Regulation of tumor cell growth at organ-specific metastases. In Vivo 1992;6(4):325-331.

5. Cooper CR, Chay CH, Gendernalik JD, Lee HL, Bhatia J, Taichman RS, McCauley LK, Keller ET, Pienta KJ. Stromal factors involved in prostate carcinoma metastasis to bone. Cancer 2003;97(3 Suppl):739-747.

6. Motamed K. SPARC (osteonectin/BM-40). Int J Biochem Cell Biol 1999;31(12):1363-1366.

7. Clark CJ, Sage EH. A prototypic matricellular protein in the tumor microenvironment-Where there's SPARC, there's fire. J Cell Biochem 2008;104(3):721-732.

8. Tai IT, Tang MJ. SPARC in cancer biology: Its role in cancer progression and potential for therapy. Drug Resist Updates 2008;11(6):231-246.

9. Podhajcer OL, Benedetti LG, Girotti MR, Prada F, Salvatierra E, Llera AS. The role of the matricellular protein SPARC in the dynamic interaction between the tumor and the host. Cancer Metastasis Rev 2008;27(4):691-705.

10. Framson PE, Sage EH. SPARC and tumor growth: Where the seed meets the soil? J Cell Biochem 2004;92(4):679-690.

11. Emerson RO, Sage EH, Ghosh JG, Clark JI. Chaperone-like activity revealed in the matricellular protein SPARC. J Cell Biochem 2006;98(4):701-705.

12. Moser M, Legate KR, Zent R, Fassler R. The tail of integrins, talin, and kindlins. Science 2009;324(5929):895-899.

13. Barker TH, Baneyx G, Cardo-Vila M, Workman GA, Weaver M, Menon PM, Dedhar S, Rempel SA, Arap W, Pasqualini R, Vogel V, Sage EH. SPARC regulates extracellular matrix organization through its modulation of integrin-linked kinase activity. J Biol Chem 2005;280(43):36483-36493.

14. Brekken RA, Puolakkainen P, Graves DC, Workman G, Lubkin SR, Sage EH. Enhanced growth of tumors in SPARC null mice is associated with changes in the ECM. J Clin Invest 2003; 111(4):487-495.
15. Puolakkainen PA, Brekken RA, Muneer S, Sage EH. Enhanced growth of pancreatic tumors in SPARC-null mice is associated with decreased deposition of extracellular matrix and reduced tumor cell apoptosis. Mol Cancer Res 2004;2(4):215-224.

16. Puolakkainen PA, Bradshaw AD, Brekken RA, Reed MJ, Kyriakides T, Funk SE, Gooden MD, Vernon RB, Wight TN, Bornstein P, Sage EH. SPARC-thrombospondin-2-double-null mice exhibit enhanced cutaneous wound healing and increased fibrovascular invasion of subcutaneous polyvinyl alcohol sponges. J Histochem Cytochem 2005;53(5):571-581.

17. Bradshaw AD, Reed MJ, Sage EH. SPARC-null mice exhibit accelerated cutaneous wound closure. J Histochem Cytochem 2002;50(1):1-10.

18. Arnold SA, Brekken RA. SPARC: A matricellular regulator of tumorigenesis. J Cell Comm Signal 2009;3(3-4):255-273.

19. Girotti MR, Fernandez M, Lopez JA, Camafeita E, Fernandez EA, Albar JP, Benedetti LG, Valacco MP, Brekken RA, Podhajcer OL, Llera AS. SPARC promotes cathepsin B-mediated melanoma invasiveness through a collagen $\mathrm{I} /$ alpha2beta1 integrin axis. J Invest Dermatol 2011;131(12):2438-2447.

20. Thomas R, True LD, Bassuk JA, Lange PH, Vessella RL. Differential expression of osteonectin/SPARC during human prostate cancer progression. Clin Cancer Res 2000;6(3):1140-1149.

21. Jacob K, Webber M, Benayahu D, Kleinman HK. Osteonectin promotes prostate cancer cell migration and invasion: A possible mechanism for metastasis to bone. Cancer Res 1999;59(17): 4453-4457.

22. Said N, Frierson HF Jr, Chernauskas D, Conaway M, Motamed $\mathrm{K}$, Theodorescu D. The role of SPARC in the TRAMP model of prostate carcinogenesis and progression. Oncogene 2009; 28(39):3487-3498.

23. Kapinas K, Lowther KM, Kessler CB, Tilbury K, Lieberman JR, Tirnauer JS, Campagnola P, Delany AM. Bone matrix osteonectin limits prostate cancer cell growth and survival. Matrix Biol 2012;31(5):299-307.

24. Mizokami A, Koh E, Izumi K, Narimoto K, Takeda M, Honma S, Dai J, Keller ET, Namiki M. Prostate cancer stromal cells and LNCaP cells coordinately activate the androgen receptor through synthesis of testosterone and dihydrotestosterone from dehydroepiandrosterone. Endocr Relat Cancer 2009;16(4): 1139-1155.

25. Izumi K, Mizokami A, Li YQ, Narimoto $K$, Sugimoto $K$ Kadono Y, Kitagawa Y, Konaka H, Koh E, Keller ET, Namiki M. Tranilast inhibits hormone refractory prostate cancer cell proliferation and suppresses transforming growth factor beta1associated osteoblastic changes. Prostate 2009;69(11):12221234.

26. de Souza PL, Russell PJ, Kearsley J. Role of the Akt pathway in prostate cancer. Curr Cancer Drug Targets 2009;9(2):163-175.

27. Goel HL, Li J, Kogan S, Languino LR. Integrins in prostate cancer progression. Endocr Relat Cancer 2008;15(3):657-664.

28. Ingber DE. Can cancer be reversed by engineering the tumor microenvironment? Semin Cancer Biol 2008;18(5):356-364.

29. Kim Y, Stolarska MA, Othmer HG. The role of the microenvironment in tumor growth and invasion. Prog Biophys Mol Biol 2011;106(2):353-379.

30. DiMartino JF, Lacayo NJ, Varadi M, Li L, Saraiya C, Ravindranath Y, Yu R, Sikic BI, Raimondi SC, Dahl GV. Low or absent SPARC expression in acute myeloid leukemia with MLL rearrangements is associated with sensitivity to growth inhibition by exogenous SPARC protein. Leukemia 2006;20(3): 426-432. 
31. Tripodo C, Sangaletti S, Guarnotta C, Piccaluga PP, Cacciatore M, Giuliano M, Franco G, Chiodoni C, Sciandra M, Miotti S, Calvaruso G, Care A, Florena AM, Scotlandi K, Orazi A, Pileri SA, Colombo MP. Stromal SPARC contributes to the detrimental fibrotic changes associated with myeloproliferation whereas its deficiency favors myeloid cell expansion. Blood 2012; 120(17):3541-3554.

32. McCabe NP, Kerr BA, Madajka M, Vasanji A, Byzova TV. Augmented osteolysis in SPARC-deficient mice with bone-residing prostate cancer. Neoplasia 2011;13(1):31-39.

33. Sarker D, Reid AH, Yap TA, de Bono JS. Targeting the PI3K/AKT pathway for the treatment of prostate cancer. Clin Cancer Res 2009;15(15):4799-4805.

34. Pommery N, Henichart JP. Involvement of PI3K/Akt pathway in prostate cancer-Potential strategies for developing targeted therapies. Mini Rev Med Chem 2005;5(12):1125-1132.

35. Bhoopathi P, Gorantla B, Sailaja GS, Gondi CS, Gujrati M, Klopfenstein JD, Rao JS. SPARC overexpression inhibits cell proliferation in neuroblastoma and is partly mediated by tumor suppressor protein PTEN and AKT. PLoS ONE 2012; 7(5):e36093.

36. Thomas SL, Alam R, Lemke N, Schultz LR, Gutierrez JA, Rempel SA. PTEN augments SPARC suppression of proliferation and inhibits SPARC-induced migration by suppressing SHC-RAFERK and AKT signaling. J Neurooncol 2010;12(9):941-955.

37. Lee YC, Jin JK, Cheng CJ, Huang CF, Song JH, Huang M, Brown WS, Zhang S, Yu-Lee LY, Yeh ET, McIntyre BW, Logothetis CJ, Gallick GE, Lin SH. Targeting constitutively activated beta1 integrin inhibits prostate cancer metastasis. Mol Cancer Res 2013 [Epub ahead of print].

38. Tsaur I, Makarevic J, Juengel E, Gasser M, Waaga-Gasser AM, Kurosch M, Reiter M, Wedel S, Bartsch G, Haferkamp A, Wiesner C, Blaheta RA. Resistance to the mTOR-inhibitor RAD001 elevates integrin alpha2- and beta1-triggered motility, migration and invasion of prostate cancer cells. Br J Cancer 2012;107(5):847-855.

39. Fornaro M, Tallini G, Bofetiado CJ, Bosari S, Languino LR. Down-regulation of beta 1C integrin, an inhibitor of cell proliferation, in prostate carcinoma. Am J Pathol 1996;149(3): 765-773.

40. Perlino E, Lovecchio $M$, Vacca RA, Fornaro M, Moro L, Ditonno P, Battaglia M, Selvaggi FP, Mastropasqua MG, Bufo $\mathrm{P}$, Languino LR. Regulation of mRNA and protein levels of beta1 integrin variants in human prostate carcinoma. Am J Pathol 2000;157(5):1727-1734.

41. Moran-Jones K, Ledger A, Naylor MJ. beta1 integrin deletion enhances progression of prostate cancer in the TRAMP mouse model. Sci Rep 2012;2:526.

42. Weaver MS, Workman G, Sage EH. The copper binding domain of SPARC mediates cell survival in vitro via interaction with integrin beta1 and activation of integrin-linked kinase. J Biol Chem 2008;283(33):22826-22837.

43. Jones EV, Bernardinelli Y, Tse YC, Chierzi S, Wong TP, Murai KK. Astrocytes control glutamate receptor levels at developing synapses through SPARC-beta-integrin interactions. J Neurosci 2011;31(11):4154-4165. 